\title{
Curvas de maturação da uva 'Tannat' (Vitis vinifera L.) para a elaboração de vinho tinto ${ }^{1}$
}

\section{Maturation curves of 'Tannat' grape (Vitis vinifera $L$.) for red winemaking}

\author{
Sérgio Ruffo Roberto ${ }^{2 *}$; Fábio Yamashita ${ }^{3}$; Éverton Allen Brenner"; \\ Alessandro Jefferson Sato ${ }^{4}$; Cristiano Ezequiel dos Santos ${ }^{5}$; Werner Genta ${ }^{6}$
}

\section{Resumo}

O trabalho teve como objetivo caracterizar a maturação da videira 'Tannat' (Vitis vinifera L.) cultivada no norte do Estado do Paraná para a elaboração de vinho tinto. A área experimental foi instalada em uma propriedade comercial pertencente à Vinícola Intervin ${ }^{\circledR}$, no município de Maringá, PR. O vinhedo foi estabelecido em agosto de $2000 \mathrm{e}$ as plantas foram conduzidas no sistema latada no espaçamento de 4,0 $\mathrm{m} \times 1,5 \mathrm{~m}$, enxertadas sobre o porta-enxerto 'IAC 766 Campinas'. As avaliações tiveram início a partir da poda de produção, realizada no fim do inverno de 2003. O delineamento experimental foi o inteiramente casualizado com 20 repetições, sendo cada parcela constituída por uma planta. As curvas de maturação da uva 'Tannat' foram determinadas através da análise das características químicas de suas bagas, como teor de sólidos solúveis totais (SST), acidez titulável (AT) e índice de maturação (SST/AT), as quais foram avaliadas semanalmente a partir do início da maturação dos cachos até 7 dias após a colheita, através da coleta de 300 bagas em cada amostragem. Obteve-se, através de análise de regressão, o comportamento das variáveis analisadas em função do tempo. Pelos resultados obtidos conclui-se que: as curvas de evolução dos teores de SST, AT e SST/AT da uva 'Tannat' se ajustam ao modelo cúbico e; os valores médios de SST, AT e SST/AT que a uva 'Tannat' atinge durante a colheita são de $21,20^{\circ} \mathrm{Brix}$, $1,04 \%$ de ácido tartárico e 20,38, respectivamente, o que indica uma boa adaptação para a elaboração de vinho tinto na região.

Palavras-chave: Videira, sólidos solúveis totais, acidez titulável.

\footnotetext{
Abstract

The objetive of this research was to characterize the maturation of 'Tannat' grape (Vitis vinifera L.) produced in the northwest of Parana state, for red winemaking. The experimental area was established in a commercial vineyard of Vinícola Intervin ${ }^{\circledR}$, Maringá, PR. The vineyard was planted in August of 2000 and the vines were trained in a pergola system, in a 4.0 x $1.0 \mathrm{~m}$ spacing, budded on 'IAC 766 Campinas' rootstock. The evaluations started from the winter pruning of 2003. The random design was used as the statistical model with 20 replications and each plot was composed by one tree. The maturation curves of

1 Parte do projeto apoiado pela Fundação Araucária de Apoio ao Desenvolvimento Científico e Tecnológico do Paraná.

2 Professor Adjunto e Pesquisador do CNPq em Produtividade em Pesquisa. Área de Fruticultura. Universidade Estadual de Londrina (UEL). Departamento de Agronomia. E-mail: sroberto@uel.br

3 Professor Adjunto. Área de Pós-Colheita de Frutas e Hortaliças. UEL. Depto. de Tecnologia de Alimentos e Medicamentos,

${ }^{4}$ Acadêmico do Curso de Graduação em Agronomia da UEL e Bolsista de Iniciação Científica - PIBIC/CNPq.

5 Aluno regular do Curso de Pós-Graduação em Agronomia, Área de Concentração em Fitotecnia, UEL e bolsista da CAPES.

${ }^{6}$ Eng. Agr. da ANPEF - Associação Norte Paranaense de Estudos em Fruticultura. Consultor em Fruticultura. Marialva, PR.

* Autor para correspondência.
} Londrina, PR 
'Tannat' grape were determined through chemical characteristic analysis of berries, such as total soluble solids (TSS), titratable acidity (TA) and maturation index (TSS/TA), which were evaluated weekly from early ripening to 7 days after harvest, processing 300 berries per sampling. Through regression analysis, the performance of these chemical characteristics was evaluated over time. It was possible to conclude that: the curves of TSS, TA and TSS/TA were well-fitted to the cubic model and; the 'Tannat' grape reached $21.20^{\circ}$ Brix, $1.04 \%$ of tartaric acid and 20.38 of maturation index during harvest, what indicates a good performance of this cultivar for red winemaking at the local condition.

Key words: Grapevine, total soluble solids, titratable acidity.

\section{Introdução}

A videira 'Tannat' (Vitis vinifera L.) é originária da região de Madiran, no sul da França, onde está sua maior área de cultivo. É a principal cultivar vinífera do Uruguai, onde, sob a denominação Harriague, ocupa mais de $30 \%$ da área de vinhedos. Foi introduzida no Rio Grande do Sul em 1947, procedente da Argentina. Após vários anos de avaliação pela pesquisa, a 'Tannat' tem demonstrado potencialidade como alternativa na Serra Gaúcha, tendo sido processados em 2003 ao redor de 2.300.000 litros desta uva naquele Estado (EMBRAPA, 2004).

O vinho da 'Tannat' é rico em cor, em taninos e extrato seco, exigindo envelhecimento para ser consumido. Em sua região de origem, no sul da França, o vinho de 'Tannat' é cortado com vinhos de outras cultivares, entre as quais a 'Cabernet Franc', para obtenção dos vinhos de apelação de origem controlada. No Rio Grande do Sul, é recomendada para elaboração de vinho tinto para corte (CAMARGO, 1994), bem como vinho varietal.

No Brasil, tem-se verificado que a comercialização de vinhos tintos finos tem aumentando ao longo das últimas duas décadas. Em 1980, foram comercializados no país 7.244.385 litros de vinho tinto fino, enquanto que em 2001, o volume foi de 12.112.495 litros desta bebida, o que representa um incremento significativo nos últimos onze anos no país (EMBRAPA, 2004).

Uma vez que a uva 'Tannat' tem se mostrado promissora no Brasil para a elaboração de vinho tinto fino, o seu cultivo na região norte do Paraná pode propiciar uma alternativa para a diversificação de uvas na região, tendo em vista que o sistema atual encontra-se atualmente voltado para a produção de uvas de mesa. Ações como essa podem proporcionar uma maior rentabilidade na exploração vitícola na região, através do destino de parte da produção para a elaboração de vinho, agregando valor à produção. Face ao grande e crescente volume de produção de uvas de mesa, o que tem acarretado baixos rendimentos em algumas safras, alguns produtores da região norte-noroeste do Paraná, têm buscado o processamento da produção visando uma maior rentabilidade da cultura, porém empregando variedades pouco aptas para estes fins.

Assim, o cultivo de videiras destinadas à elaboração de vinho tinto fino, como a 'Tannat', é uma alternativa para a verticalização da produção de uvas na região noroeste do Paraná. Entretanto, nenhuma informação acerca das características da maturação desta videira no Estado encontra-se disponível.

Tendo em vista estes aspectos, o presente trabalho teve por objetivo caracterizar o comportamento da maturação da uva 'Tannat' para a elaboração de vinho tinto fino na região noroeste do Paraná.

\section{Materiais e Métodos}

O trabalho foi conduzido em uma propriedade comercial pertencente à Vinícola Intervin ${ }^{\circledR}$, localizada no município de Maringá, PR. O vinhedo experimental da uva 'Tannat' (Vitis vinifera L.) foi estabelecido em agosto de 2000 e as plantas estão sendo conduzidas no sistema latada no espaçamentos de 4,0 m x 1,5 m, sobre o porta-enxerto 'IAC 766 Campinas'.

O delineamento empregado foi o inteiramente casualizado com 20 repetições, sendo cada parcela constituída por uma única planta (BOLIANI; 
PEREIRA, 1996; LEÃO; PEREIRA, 2001). As avaliações tiveram início em setembro de 2003, a partir da poda de frutificação, e se estenderam até a colheita dos frutos.

Para a realização da poda de frutificação, esperou-se pelo início do inchamento das gemas, e em seguida, foi aplicado o regulador cianamida hidrogenada a 2,5\% para a quebra da dormência das gemas das videiras, com o objetivo de se obter brotação uniforme das mesmas. A poda de produção foi realizada deixando-se 4 ou 5 gemas por esporão.

As curvas de maturação da uva 'Tannat' foram determinadas através da análise das características químicas de suas bagas, como teor de sólidos solúveis totais (SST), acidez titulável (AT) e índice de maturação (SST/AT), as quais foram avaliadas semanalmente a partir do início da maturação dos cachos ("véraison") até 7 dias após a colheita, através da coleta de 300 bagas em cada amostragem (RIZZON; MIELE, 2002), divididas em 10 subamostras de 30 bagas cada, por métodos químicos (INSTITUTO ADOLFO LUTZ, 1985).

As análises foram realizadas no Laboratório de Frutas pertencente ao Centro de Ciências Agrárias da Universidade Estadual de Londrina, PR. O teor de SST foi determinado em refratômetro digital de bancada com compensação automática de temperatura (Modelo DR 301-95, Krüss Optronic, Alemanha) através da trituração das amostras, e o resultado expresso em ${ }^{\circ}$ Brix. A determinação da AT foi realizada por titulação do suco com solução padronizada de $\mathrm{NaOH} \quad 0,1 \mathrm{~N}$ em titulador potenciométrico digital (Modelo Tritoline Easy, Schott Geräte, Alemanha), e o resultado expresso em porcentagem de ácido tartárico. A partir dos dados obtidos, obteve-se, através de análise de regressão, o comportamento das variáveis analisadas (SST, AT e STT/AT das bagas) em função do tempo (BOLIANI, 1994; ROBERTO et al., 2002a, 2002b). Para a determinação dos coeficientes e parâmetros estatísticos das regressões foi utilizado o programa Statistica $^{\circledR} 5.0$ (STATSOFT, 1995).

\section{Resultados e Discussão}

A evolução do teor de SST seguiu tendência de um crescimento positivo, e o modelo de equação que melhor se ajustou foi o de regressão cúbica $\left(\mathrm{R}^{2}=\right.$ 0,98). O início da fase de maturação dessa videira, considerada quando $50 \%$ das bagas mudaram de cor, ocorreu aos 55 dias após o florescimento, caracterizando o início da maturação das bagas. No momento da colheita, a videira 'Tannat' apresentou média de 21,20 ${ }^{\circ}$ Brix (Figura 1).

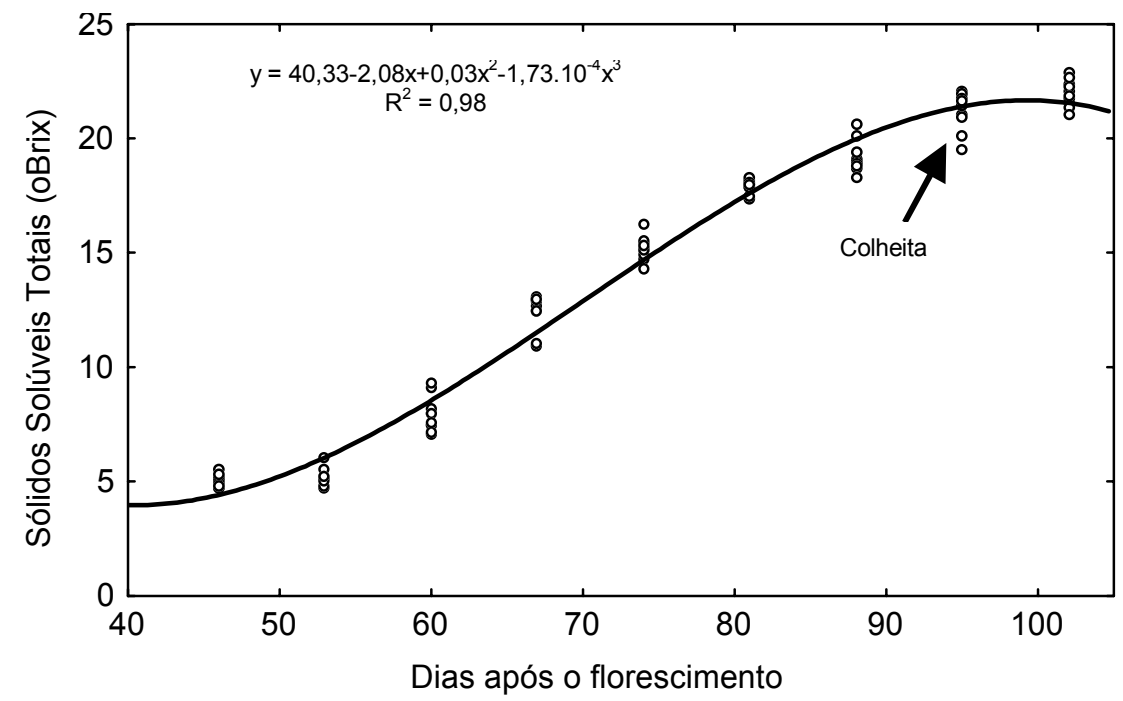

Figura 1. Evolução do teor sólidos solúveis totais ('Brix) no mosto durante a maturação da videira 'Tannat' (Vitis vinifera L.) em Maringá, PR. 2004. 
De acordo Giovannini (2003), a videira 'Tannat' é colhida na Serra Gaúcha com teor médio de SST igual a 20,1 ${ }^{\circ}$ Brix. Lima et al. (2003), descrevem que no Submédio do Vale do São Francisco (BA), esta videira é colhida com $18,3{ }^{\circ}$ Brix em média. Assim, a alta concentração de SST no mosto das bagas da videira 'Tannat' durante a colheita em Maringá (21,20 ํㅜix), indicam uma boa adaptação desta cultivar na região.

Segundo Blouin e Guimberteau (2000), durante a fase de crescimento herbáceo da baga, o teor de açúcar é baixo. Nesse período, ele é utilizado para o desenvolvimento do fruto, sobretudo para o crescimento e maturação da semente. Na fase da maturação da uva, uma modificação metabólica na utilização do açúcar ocasiona uma acúmulo rápido deste componente na baga, fase essa conhecida como "véraison", até que um patamar máximo seja atingido. Entretanto, dependendo das condições de clima local e da variedade, nem sempre as uvas podem ser colhidas na fase que atingem seu maior teor de açúcares, pois a ocorrência de podridões, ataque de pássaros e rachadura das bagas devido às chuvas, propiciam o surgimento da podridão ácida, a qual prejudica a vinificação.

Para a AT, o modelo de equação que melhor se ajustou foi o da regressão cúbica $\left(\mathrm{R}^{2}=0,93\right)$. A redução da AT nas bagas foi mais pronunciada a partir dos 60 dias após o florescimento, sendo que próximo à colheita, essa redução foi menos evidente. No momento da colheita, a uva 'Tannat' apresentou média de 1,04\% de acidez (Figura 2).

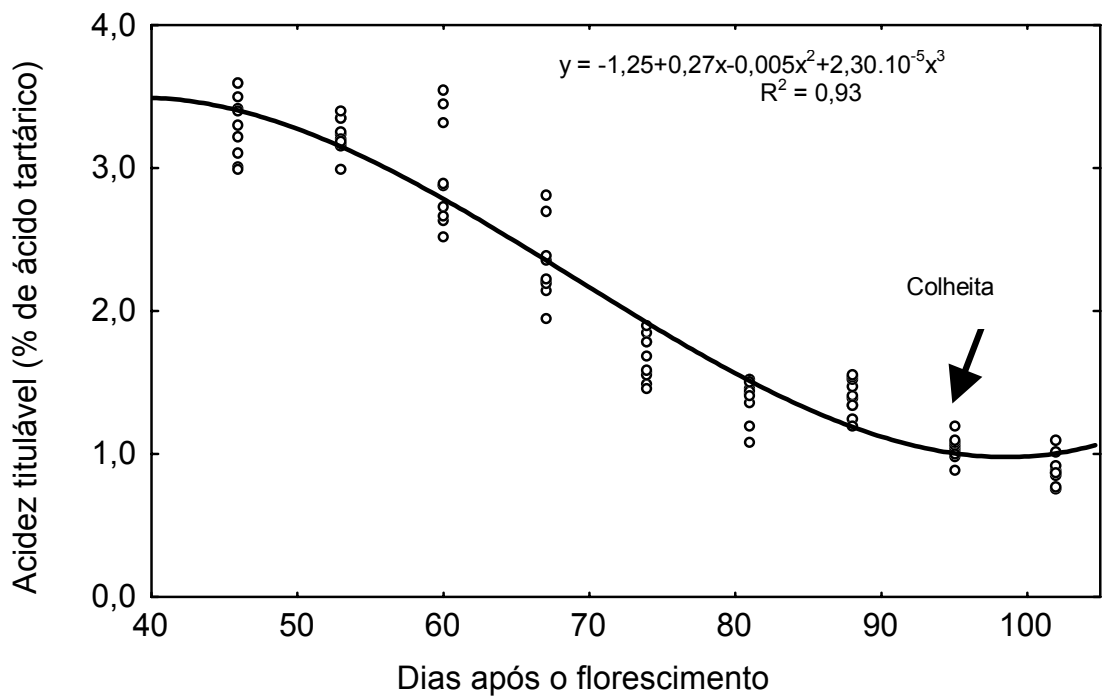

Figura 2. Evolução da acidez titulável (\% de ácido tartárico) no mosto durante a maturação da videira 'Tannat' (Vitis vinifera L.) em Maringá, PR. 2004.

Mullins et al. (1994) descreveram que a concentração de ácidos orgânicos presentes nas bagas, cerca de $90 \%$ são os ácidos tartárico e málico, decresce significativamente a partir do início da maturação dos frutos, devido a diversos fatores. A partir desta fase, verifica-se que não ocorre uma redução da quantidade de ácido tartárico "por baga" e sim sua diluição crescente devido ao aumento do volume das mesmas. Por outro lado, uma vez que o ácido málico é sintetizado via sacarose, observa-se a partir do início da maturação que a concentração deste ácido sofre significativa redução, devido à alteração do metabolismo da sacarose produzida pela planta (POSSNER; RUFFNER; RAST, 1983), até que o seu teor se estabilize em um patamar constante, próximo à maturação plena dos cachos (CARROL; MARCY, 1982). Além desses fatores, Borgogno et al. (1984), descreveram que essa diminuição do teor de AT no decorrer da fase de maturação da uva é devido também à sua salificação. 
Para a relação SST/AT, o modelo de equação que melhor se ajustou para a uva 'Tannat' foi o cúbico $\left(\mathrm{R}^{2}=0,96\right)$. Pôde ser constatado que, até o $55^{\circ}$ dia após o florescimento, esta relação manteve-se estável, porém a partir desta data, onde iniciou-se o amadurecimento das bagas, observou-se um incremento acelerado até a última avaliação realizada aos 7 dias após a colheita. No momento da colheita, a videira 'Tannat' apresentou média de 20,38 em relação ao índice de maturação (SST/AT) (Figura 3).

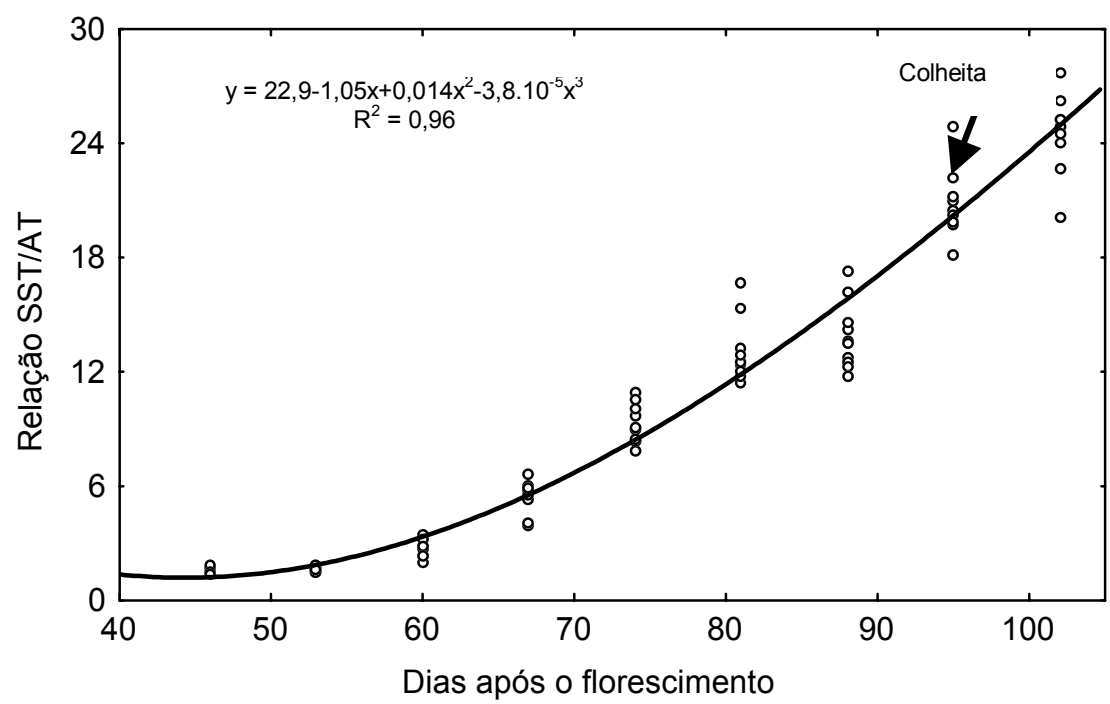

Figura 3. Evolução da relação sólidos solúveis totais/acidez titulável (SST/AT) no mosto durante a maturação da videira 'Tannat' (Vitis vinifera L.) em Maringá, PR. 2004.

Segundo Rizzon e Miele (2002), a relação SST/ AT é um dos índices utilizados para determinação da maturação da uva e de sua qualidade enológica, e sua utilização como índice de maturação da uva deve ser feita com cuidado, pois um aumento da SST nem sempre corresponde a igual redução de AT. Porém, este índice pode indicar o equilíbrio ideal entre açúcar e acidez de uma variedade para uma determinada região, tendo como referência uma safra considerada ótima do ponto de vista enológico.

Os resultados apresentados neste trabalho reforçam as afirmações de Gonçalves et al. (2002), que relataram que os atributos de qualidade, tais como sólidos solúveis totais e acidez titulável, apresentam fundamental importância no monitoramento do ponto de colheita dos frutos de videira, possibilitando um melhor controle de qualidade da matéria-prima a ser utilizada na elaboração de vinhos.

Os resultados aqui apresentados, embora propiciem boas indicações sobre as características da maturação da uva 'Tannat' no noroeste do Paraná para a elaboração de vinho tinto fino, estes devem ser considerados como preliminares, ou seja, observações do comportamento desta uva destinada à elaboração de vinho tinto fino na região deverão ser realizados durante vários ciclos produtivos, para que o seu potencial possa ser devidamente avaliado e caracterizado.

\section{Conclusões}

Em função dos resultados obtidos nas condições em que foi realizado o ensaio, foi possível concluir que:

a) As curvas de evolução dos teores de SST, AT e SST/AT da uva 'Tannat' se ajustam ao modelo cúbico quando cultivadas na região noroeste do Paraná.

b) Os valores médios de SST, AT e SST/AT que a uva 'Tannat' atinge durante a colheita são de 21,20 ${ }^{\circ}$ Brix, $1,04 \%$ de ácido tartárico e 20,38, respectivamente, o que indica uma boa adaptação para a elaboração de vinho tinto na região. 


\section{Agradecimentos}

Os autores expressam seus agradecimentos à Vinícola Intervin ${ }^{\circledR}$ e à Fundação Araucária pelo apoio financeiro, e ao CNPq pela concessão das bolsas de pesquisa.

\section{Referências}

BLOUIN, J.; GUIMBERTEAU, G. Maturation et maturité des raisins. Bordeaux: Féret, 2000. 151p.

BOLIANI, A. C. Avaliação fenológica de videira Vitis vinifera L. cv. Itália e cv. Rubi na região oeste do Estado de São Paulo. 1994. 187f. Tese (Doutorado em Agronomia) - Faculdade de Ciências Agrárias e Veterinárias, Universidade Estadual Paulista, Jaboticabal, 1994.

BOLIANI, A. C.; PEREIRA, F. M. Avaliação fenológica de videiras (Vitis vinifera L.), cvs. Itália e Rubi, submetidas à poda de renovação na região oeste do Estado de São Paulo. Revista Brasileira de Fruticultura, Cruz das Almas, v.18, n.2, p.193-200, 1996.

BORGOGNO, L.; TARETTO, E.; BOLOGNA, P.; ARNULFO, C.; MORANDO, A. La maturazione dell'uva. Vignevini, Bologna, v.3, n.11, p.59-65, 1984.

CAMARGO, U. A. Uvas do Brasil. Brasília: Embrapa/SPI, 1994. (Documentos, 9).

EMBRAPA. Dados da vitivinicultura. Disponível em: $<$ http://www.cnpuv.embrapa.br>. Acesso em: 15 mar. 2004.

GIOVANNINI, E. Avaliação da adaptabilidade de cvs. para vinho fino na Campanha e na Serra Gaúcha através do teor de açúcar e da produtividade. In: CONGRESSO BRASILEIRO DE VITICULTURA E ENOLOGIA, 10., 2003, Bento Gonçalves. Anais... Bento Gonçalves: Embrapa Uva e Vinho, 2003. p.184.

GONÇALVES, C. A. A.; LIMA, L. C. O.; CHALFUN, N.N. J.; REGINA, M. A.; ALVARENGA, A. A.; SOUZA, M. T. Fenologia e qualidade do mosto de videiras 'Folha de Figo' sobre diferentes porta-enxertos, em Caldas, sul de Minas Gerais. Ciência e Agrotecnologia, Lavras, v.26, n.6, p.1178-1184, 2002.
INSTITUTO ADOLFO LUTZ. Normas analíticas do Instituto Adolfo Lutz: métodos químicos e físicos para análise dos alimentos. 3. ed. São Paulo: Instituto Adolfo Lutz, 1985. v.1.

LEÃO, P. C. S.; PEREIRA, F. M. Estudo da brotação e da fertilidade de gemas de cultivares de uvas sem sementes nas condições tropicais do vale do submédio do São Francisco. Revista Brasileira de Fruticultura, Cruz das Almas, v.23, n.1, p.30-34, 2001.

LIMA, M. A C. ; LEÃO, P. C. S.; RIBEIRO, A. P. L.; TRINDADE, D. C. G. Maturação de cultivares de uva nas condições do Submédio São Francisco. In: CONGRESSO BRASILEIRO DE VITICULTURA E ENOLOGIA, 10., 2003 , Bento Gonçalves. Anais...Bento Gonçalves: Embrapa Uva e Vinho, 2003.p.196.

MULLINS, M. G.; MULLINS, M. G.; BOUQUET, A.; WILLIAMS, L. E. Biology of the grapevine. New York: University of Cambridge, 1994.

POSSNER, D.; RUFFNER, H. P.; RAST, D. M. Regulation of malic acid metabolism in berries of Vitis vinifera. Acta Horticulturae, Wageningen, n.139, p.117-122, 1983.

RIZZON, L. A.; MIELE, A. Avaliação da cv. Cabernet Sauvignon para elaboração de vinho tinho. Ciência e Tecnologia de Alimentos, Campinas, v.22, n.2, p.192-198, 2002.

ROBERTO, S. R.; YAMASHITA, F.; KANAI, H. T.; YANO, M. Y.; MACENTE, E. S.; GENTA, W. Antecipação da maturação da uva 'Rubi' produzida fora de estação no noroeste do Paraná. Revista Brasileira de Fruticultura, Cruz das Almas, v.24, n.3, p.780-782, 2002a.

ROBERTO, S. R.; YAMASHITA, F.; KANAI, H. T.; YANO, M. Y.; MACENTE, E. S.; GENTA, W. Efeito da época do anelamento do tronco sobre as características da produção da videira 'Rubi' (Vitis vinifera L.). Acta Scientiarum, Maringá, v.24, n.5, p.1307-1312, 2002b.

STATSOFT. STATISTICA for Windows: computer program manual. Tulsa: Statsoft, 1995. 